Short Communication

\title{
Effect of Flow Rate on Corrosion Behavior and Hydrogen Evolution Potential of X65 Steel in 3.5\% NaCl Solution
}

\author{
Weiwei Kang, Zhiming Gao*, Yingjie Liu, Liqin Wang
}

School of Material Science and Technology, Tianjin University, Tianjin, 30072, China

"E-mail: gaozhiming@tju.edu.cn

doi: $10.20964 / 2019.03 .02$

Received: 19 March 2017 / Accepted: 29 December 2018 / Published: 7 February 2019

Effect of flow rate on the cathodic reaction as well as hydrogen evolution potential of X65 steel in $3.5 \% \mathrm{NaCl}$ solution were investigated using Electrochemical impedance spectroscopy (EIS) and potentiodynamic polarization. It is observed that, compared with static conditions, the charge transfer resistance values $R_{\mathrm{t}}$ decreases significantly under the condition of flowing, and the cathodic diffusion limiting current density increases with the increasing of the flow rate. In addition, the polarization curve under static conditions appears a typical hydrogen evolution potential turning point while the polarization curve under flowing condition does not. The determination of hydrogen evolution potential by means of measuring EIS under different cathodic potentials shows that the hydrogen evolution potential of X65 shifts positively to different degrees with the increasing of flow rate.

Keywords: flow rate; cathodic protection; hydrogen evolution potential; X65 steel.

\section{$\underline{\text { FULL TEXT }}$}

(C) 2019 The Authors. Published by ESG (www.electrochemsci.org). This article is an open access article distributed under the terms and conditions of the Creative Commons Attribution license (http://creativecommons.org/licenses/by/4.0/). 